\title{
How accurate is size and distance perception for very far terrestrial objects? Function and causality
}

\author{
ATSUKI HIGASHIYAMA \\ University of Osaka Prefecture, Sakai, Japan \\ and \\ KOICHI SHIMONO \\ Tokyo University of Mercantile Marine, Tokyo, Japan
}

\begin{abstract}
This study investigated absolute estimation of size and distance for natural and artificial objects at viewing distances of 1.1-15.3 km (Experiments 1 and 2) and 0.4-5.0 $\mathrm{m}$ (Experiment 3). The main results were that, regardless of distance range, size and distance estimates $\left(S^{\prime}\right.$ and $\left.D^{\prime}\right)$ were related to objective size and distance $(S$ and $D)$, respectively, by a power function with an exponent of unity, but great individual differences in exponent were obtained for the far objects. The ratio $S^{\prime} / D^{\prime}$ was reasonably represented by $S^{\prime} / D^{\prime}=K \theta^{n}$ and $S^{\prime} / D^{\prime}=\tan (a \theta+b)$, rather than $S^{\prime} / D^{\prime}=\tan \theta$, where $\theta$ is the visual angle. Partial correlations were obtained to examine whether (1) apparent size is determined by taking apparent distance into account or (2) both apparent size and apparent distance are determined directly by external stimuli. The combined data for the far objects and the data for the close objects showed that there were high correlations between $S$ and $S^{\prime}$ and between $D$ and $D^{\prime}$ and a low correlation between $D^{\prime}$ and $S^{\prime}$. The data of Experiment 2 showed that both $D^{\prime}$ and $S^{\prime}$ were highly correlated with $S, D$, and $\theta$, and there was a high positive correlation between $D^{\prime}$ and $S^{\prime}$. It was suggested that the direct-perception model is valid under some situations, but the taking-into-account model is not supported in any set of data.
\end{abstract}

In this study, we investigated perception of the size of and distance of very far objects. The perception of size and distance may not be correctly achieved for celestial objects such as the moon, the sun, and a constellation. For example, estimates of the size and distance of the moon may not be exact if you are not an astronomer. Some authors have indeed assumed that there is a perceptible maximal distance, beyond which any object is perceived to be at a constant distance and distance is not discriminated at all (Gilinsky, 1951; Indow, 1991; Luneburg, 1947; Nishi, 1930). Others have assumed that size constancy does not hold for very far objects and that the visual system tends to respond to the visual angle, rather than the distal size, of the object (Higashiyama, 1992).

How do we perceive size and distance for very far terrestrial objects? In this study, we report three experiments.

\footnotetext{
We would like to express our appreciation to Captain Matsumura and the crews of Shiojimaru, who traveled across Tokyo Bay in Experiment 2 . We would like to thank John C. Baird, Hal A. Sedgwick, and Myron L. Braunstein for their useful comments on the earlier manuscript, and thank an anonymous reviewer for his or her help in improving the English expressions. A. Higashiyama's mailing address is: Institute of Human Sciences, College of Integrated Arts and Sciences, University of Osaka Prefecture, Sakai 593, Japan. K. Shimono's mailing address is: Social Sciences Laboratory, Tokyo University of Mercantile Marine, Koto-ku, Tokyo 135, Japan.
}

We first sought to specify the distance range over which the accurate perception of size and distance would be maintained. In Experiments 1 and 2, subjects estimated absolute size and distance for the objects at viewing distances of 1-15 km at sea. For comparison, the estimates of size and distance for close objects were obtained indoors in Experiment 3.

We next sought to clarify the functional and causal relation among size estimation, distance estimation, and visual angle. To examine the functional relation among the three variables, the ratio of size estimates to distance estimates was represented as a function of visual angle. We then attempted to find a suitable equation fitted to the ratios by comparing three versions of the size-distance invariance hypothesis. The causal relation was inferred on the basis of the partial correlation analysis. The obtained correlations were then compared with those predicted from the taking-into-account model and the directperception model.

\section{Definitions and a Review of Close Objects}

Little is known about size and distance perception for very far terrestrial objects, but there are a number of studies that have been done outdoors at a distance of $1 \mathrm{~km}$ or less. By reviewing these studies, we attempted to define several terms used in our study and to show how accurate size and distance perception is at short distances. 
Size. In a classic size-perception study (Gilinsky, 1955), the variable placed at a distance of $30 \mathrm{~m}$ was matched to the standard placed at $30-1,200 \mathrm{~m}$. Under objective-size instructions, the variable increased as the distance of the standard increased (i.e., overconstancy), whereas under retinal-size instructions, the variable decreased as the distance of the standard increased (i.e., underconstancy). If the variable is constant over the distance of the standard, it is said that size constancy prevails.

Several studies of size perception at much shorter distances have also suggested the importance of the instructions to the subjects in size matching. For example, objective-size instructions lead to overconstancy (Baird \& Biersdorf, 1967; Carlson \& Tassone, 1967, their grouped data; Epstein, 1963; Smith, 1953; Wohlwill, 1963) or to constancy (Leibowitz \& Harvey, 1967, 1969); apparent- or phenomenal-size instructions lead to constancy (Epstein, 1963; Leibowitz \& Harvey, 1969, their Experiment 2) or to underconstancy (Leibowitz \& Harvey, 1967, and 1969, their Experiments 1 and 3); and retinal-size instructions lead to underconstancy (Carlson \& Tassone, 1967; Epstein, 1963; Leibowitz \& Harvey, 1967, 1969). Although the fact that size matches vary with the instructions to the subjects has been interpreted in different ways (Baird \& Wagner, 1991; Carlson, 1977; Ono, 1970), it seems that apparent instructions are likely to lead to size constancy in naturalistic situations.

Size perception has also been studied by using the method of absolute estimation, in which the subject verbally estimates size in terms of physical units, such as meters and feet. Size estimates obtained with this method seem to follow constancy or overconstancy. Joynson, Newson, and May (1965) showed that an unfamiliar object is estimated to be larger at greater viewing distances. Eriksson and Zetterberg (1975) indicated that the size estimates for a familiar object of fixed size are constant over viewing distances of 3-150 m. Higashiyama and Kitano (1991) demonstrated that size estimates for an unfamiliar object increase as the viewing distance increases from 40 to $160 \mathrm{~m}$, whereas size estimates for a familiar object remain constant over distance.

Distance. The perception of distance up to $100 \mathrm{~m}$ has been examined by using the methods of equal-appearing intervals and bisection (Gilinsky, 1955; Harway, 1963; Kuroda, 1971). In the typical situation, the subject stands at one end of an open field and directs the experimenter to move a pointer, to mark off successive increments of equal-appearing intervals. The obtained intervals enlarge as the viewing distance of the pointer increases, suggesting that apparent intervals of fixed size diminish with viewing distance. Purdy and Gibson (1955) and Tada (1956) instructed subjects to bisect a given distance. They found the close half of the distance to be somewhat larger than the far half. The results of these two studies suggest that apparent intervals of fixed size increase with viewing distance. With the method of equal-appearing intervals, on the other hand, Cook (1978) indicated that, at distances of $2 \mathrm{~m}$ or less, apparent distance is proportional to objective distance. Thus, distance estimates seem accurate as a whole, although they may depend on many factors.

Distances of more than $100 \mathrm{~m}$ have been studied by using the methods of magnitude estimation, ratio judgments, and absolute estimation; these distance estimates have been represented as power functions of objective distance (Da Silva, 1985; Sedgwick, 1986; Wiest \& Bell, 1985). Gibson and Bergman (1954), Gibson, Bergman, and Purdy (1955), and Higashiyama and Tashiro (1989, Experiment 5) reported exponents of 0.96-1.02, which means that apparent distance increases approximately as fast as objective distance. Galanter and Galanter (1973, Experiments 1, 4, and 5) reported exponents of 1.25-1.27, and Baird and Wagner (1982, Experiment 3) reported an exponent of 1.17, suggesting that apparent distance grows more rapidly than objective distance. $\mathrm{R}$. Teghtsoonian (1973) and R. Teghtsoonian and M. Teghtsoonian (1970b) reported exponents of $0.85-0.88$, suggesting that apparent distance increases more slowly than objective distance. Thus, although the exponents obtained in these studies do not completely agree with each other, the exponent for apparent distance appears close to unity.

\section{The Size-Distance Invariance Hypothesis}

The relation among apparent size, apparent distance, and visual angle has been described by the size-distance invariance hypothesis (SDIH), which states that a retinal projection or visual angle of given size determines a unique ratio of apparent size to apparent distance (Epstein, Park, \& Casey, 1961; Kilpatrick \& Ittelson, 1953; Sedgwick, 1986). From this definition, the SDIH may be formulated (Foley, 1967) as

$$
\frac{S^{\prime}}{D^{\prime}}=f(\theta),
$$

where $S^{\prime}$ is apparent size, $D^{\prime}$ is apparent distance, and $\theta$ is the visual angle.

In practice, it is important to specify the unknown function $f$ in Equation 1. We attempted to search for an explicit form of Equation 1 by fitting three versions of the SDIH to the set of data obtained in this study. The first version of the SDIH is geometric (Akishige, 1961; Baird, 1982; Baird \& Wagner, 1982, 1991; Gogel \& Da Silva, 1987a, 1987b; Ueno, 1962). If the ratio of apparent size to apparent distance is determined so as to conform to the geometric relation among objective size, objective distance, and visual angle, then we obtain

$$
\frac{S^{\prime}}{D^{\prime}}=\tan \theta .
$$

Note that $S^{\prime} / D^{\prime}=\theta$ holds for small visual angles, because $\tan \theta$ approximates $\theta$.

The second version of the SDIH is psychophysical. In the situations where only binocular convergence and ret- 
inal disparity were available, Foley $(1967,1968)$ and Oyama (1974) assumed $S^{\prime} / D^{\prime}$ to vary as a power function of visual angle:

$$
\frac{S^{\prime}}{D^{\prime}}=K \theta^{n}
$$

where $K$ and $n$ are constants. The mean exponent obtained by the two authors was about 1.45 .

The third version of the SDIH is to replace $\theta$ in Equation 1 by apparent visual angle $\theta^{\prime}$ (McCready, 1965, 1985, 1986): $S^{\prime} / D^{\prime}=f\left(\theta^{\prime}\right)$. If $S^{\prime} / D^{\prime}$ equals $\tan \theta^{\prime}$, and if $\theta^{\prime}$ is a linear function of $\theta$, then we obtain

$$
\frac{S^{\prime}}{D^{\prime}}=\tan \theta^{\prime}=\tan (a \theta+b)
$$

where $a$ and $b$ are constants. Since visual angle is generally overestimated (Foley, 1965; Higashiyama, 1992), the value of $a$ is assumed to be larger than unity.

Even if the functional relation among apparent size, apparent distance, and visual angle is specified, the causal network among these three variables remains unsettled. The most classical perceptual theory has postulated that retinal image size is transformed into apparent size after taking apparent distance into account (see Epstein, 1973, 1977 , for review). In other words, size perception presupposes distance perception. If we attain accurate distance perception, size perception is also accurate. Similarly, if there is no information about distance, apparent size is determined by visual angle alone. This model seems to have been first proposed by the 11th-century Arabic scientist Ibn al-Haytham as an explanation of the moon illusion (Plug \& H. E. Ross, 1989; H. E. Ross \& G. M. Ross, 1976) and subsequently appeared in a more refined form in textbooks (Goldstein, 1989; Kaufman, 1974; Rock, 1975).

Another model assumes that apparent size and apparent distance are not causally related, but are determined separately by picking up invariant optical structure involved in retinal stimulation. This model has been derived from Gibson's $(1950,1979)$ ecological approach, which emphasizes the role of the ground in visual perception. Consider, for example, apparent size and apparent distance of a cylinder placed on the ground with texture gradient (Gibson, 1950, p. 182; Gibson, 1979, p. 163). In this case, apparent distance is determined by the texture gradient on the ground and apparent size is determined by the number of the units of texture hidden by the cylinder. In short, apparent size and apparent distance are determined separately by the same stimulus variable.

From a similar ecological point of view, Sedgwick (1986) proposed the horizon-ratio principle, in which the objective size $(S)$ for a very far terrestrial object, when viewed from an observation point $(h)$ above the ground, is approximately specified by the visual angle subtended by the object $(\theta)$, with reference to the visual angle sub- tended by the horizon line and the lower end of the object $\left(\theta_{l}\right): S / h=\theta / \theta_{l}$. This relation suggests that apparent size for an object seen in front of the horizon line can be determined by the two visual angles $\theta$ and $\theta_{l}$. In both the texture-gradient theory and the horizon-ratio principle, it is not necessary for the visual system to take apparent distance into account to achieve apparent size.

In seeking to determine the proper causal network among apparent size, apparent distance, and visual angle, simple and partial correlations were obtained among them. In finding a proper model, we relied on partial correlation rather than simple correlation, because, even if simple correlation is high, it is likely to be spurious (Asher, 1976; Cohen \& Cohen, 1975; Simon, 1954). On the basis of a set of partial correlations, Oyama (1974, 1977) has indeed inferred causal connections in various branches of perception. From the taking-into-account model for size and distance perception, positive partial correlations should be obtained between apparent size and apparent distance and between apparent size and visual angle. On the other hand, from the direct-perception model, positive partial correlations should be obtained between apparent size and objective size and between apparent distance and objective distance, and there should be a low partial correlation between apparent size and apparent distance. The most critical feature discerning the two models seems to be whether a positive partial correlation is obtained between apparent size and apparent distance.

\section{METHOD}

\section{Experiment 1}

Three experiments were conducted: the first two were done at sea, and the last was done in a well-illuminated laboratory room. In Experiment 1, the estimates of size and distance were obtained at a sightseeing location, Washuzan, in the Inland Sea of Japan. Since the viewing position was on a hillside about $64.5 \mathrm{~m}$ above the sea, a number of islands and suspension bridges between them were seen below horizontal eye level. Eleven islands (Matsu, Kama, Buto, Iwakuro, Naga, Wasa, Mukuchi, Koyo, Hon, Ushi, and Hiro) and three legs supporting the bridges were used as the targets for distance estimation. The objective distances to these targets from the subject ranged from 1.1 to $10.4 \mathrm{~km}$. Figure 1 shows the positions of these targets and the objective distances to them from the viewing position. For Matsu, Kama, Buto, Iwakuro, Wasa, and Koyo, the viewing distance was defined as the distance to the nearest beach on each island. For Naga, Mukuchi, Hon, Ushi, and Hiro, the viewing distance was defined as the distance to the crest of the highest mountain in each island. These viewing distances were read directly from a map drawn on a scale of $1-25,000$. Note that the height of observation in this experiment does not greatly change the viewing distances of the targets. For example, the viewing distance of $1,100 \mathrm{~m}$ when measured on the sea surface increases only to $1,102 \mathrm{~m}$ when measured from Washuzan.

As the targets for size estimation, we selected three islands (Koyo, Matsu, and Kama) from among the 11 islands used for distance estimation. Since none of these islands were overlapped by the other islands, they could be seen in their entirety. The total lengths of Koyo, Matsu, and Kama were $0.40,0.45$, and $1.00 \mathrm{~km}$, and the distances up to the nearest beaches of the islands were $4.8,1.2$, and $1.9 \mathrm{~km}$ from the subjects, respectively. The subjects were 36 


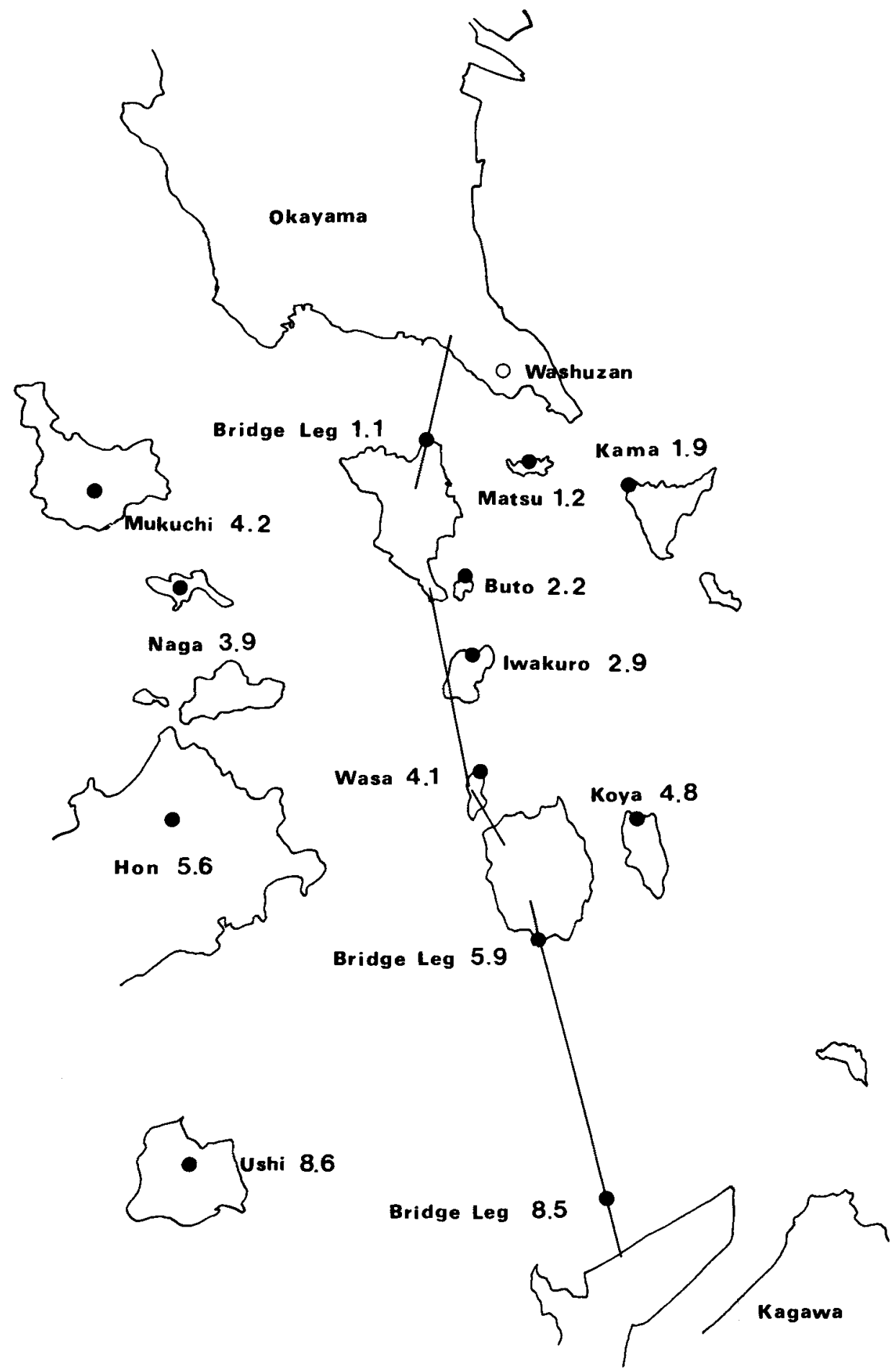

Figure 1. Eleven islands and three legs of bridges that were used as targets for size and distance estimation. The number attached to each target is the objective distance from Washuzan (denoted by open circle) in kilometers. The lines connecting the islands represent the suspension bridges. Hiro Island $(10.4 \mathrm{~km})$ is not drawn in Figure 1; it is positioned at the left of Hon Island. 
sightseers who happened to visit Washuzan (26 males, 15-68 years old, and 10 females, 27-36 years old).

Experiment 1 was performed on a cloudy day in May 1991. AII targets were discriminated without confusion. The farthest target, Hiro Island, appeared faint and blurred but was still differentiated from the neighboring islands. The subject was asked to indicate the distances to the beaches or mountains of the 14 targets, with verbal estimates expressed in meters, kilometers, or some combination thereof. The estimation order of targets was randomized for each subject. For the islands of Koyo, Matsu, and Kama, the subject indicated not only their distances but also the total lengths with verbal estimates. No limitation of the time needed for estimation was imposed on the subject.

\section{Experiment 2}

In Experiment 2, the estimates of size and distance were obtained on a ship that traveled along the shoreline of Tateyama Bay in Chiba Prefecture. Figure 2 shows five positions (A-E) where the ship stopped for estimation of size and distance. At each stopping position, several natural and artificial objects were selected as the targets for distance estimation: Uki Island $(2.0 \mathrm{~km})$ and two capes (Daibusa, $8.1 \mathrm{~km}$, and Sunosaki, $15.3 \mathrm{~km}$ ) were seen at Position A, Inose Island $(1.1 \mathrm{~km})$ and two capes (Daibusa, $3.2 \mathrm{~km}$, and Sunosaki, $10.4 \mathrm{~km})$ at Position B, one cliff $(1.7 \mathrm{~km})$ and Sunosaki Cape $(6.8 \mathrm{~km})$ at Position C, a breakwater $(1.0 \mathrm{~km})$, Kikuya Hotel $(2.9 \mathrm{~km})$, Mount Shiro $(4.3 \mathrm{~km})$, and Sunosaki Cape $(8.2 \mathrm{~km})$ at Position D, and Oki Island $(1.5 \mathrm{~km})$ and Daibusa Cape $(3.3 \mathrm{~km})$ at Position E. These targets and their distances from each stopping position are indicated in Figure 2. All the viewing distances are the distances to nearest points on the targets. The viewing distances were measured by a tellurometer on the ship, and the objective sizes of the targets were read from a map drawn on a scale of $1-25,000$. The height of observation was about $4.9 \mathrm{~m}$ above the sea. Sunosaki Cape viewed from Positions A and B appeared very faint, but all the subjects could identify it.

Six targets were used for size estimation: Uki Island ( $350 \mathrm{~m}$ long) seen at Position A, Inose Island ( $28 \mathrm{~m}$ long) seen at Position B, the cliff ( $84 \mathrm{~m}$ high) and Tomiura Ground Hotel (130 $\mathrm{m}$ wide) seen at Position C, Kikuya Hotel ( $55 \mathrm{~m}$ wide) seen at Position D, and Oki Island ( $380 \mathrm{~m}$ long) seen at Position E.

The subjects were 6 professors ( 5 males and 1 female), who studied law, literature, economics, engineering, and logistics, and 22 students ( 21 males and 1 female); their ages ranged from 21 to 58 years. Before boarding the ship, the subjects were told that they would be judging apparent size and apparent distance of the objects seen on the sea, but they were not familiar with either the places to which they were traveling or the targets to be judged there.

This experiment was performed on two different clear days in March 1992. On the initial day, 13 of the subjects boarded the ship, which traveled in the order of Positions A, B, C, D, and E; on the other day, the remaining 15 subjects were on the ship, which traveled in the reverse order. On both trips, the subjects were tested in a group. At each stopping position, the subjects went on deck and wrote down the distance estimates (or both size and distance estimates) of each targets on a sheet of paper under the direction of the experimenter. While writing the estimates and moving from one stopping position to the next, the subjects were asked not to talk to each other about what they wrote on the sheet. The subjects were allowed to use whatever length units they preferred. Twenty subjects consistently used meters, kilometers, or some combination thereof; 8 subjects used miles for distance estimation and used meters, kilometers, or some combination thereof for size estimation. No limitation of the time needed for estimation was imposed on the subjects.

\section{Experiment 3}

Experiment 3 was done in a well-illuminated laboratory room. Figure 3 shows the arrangement of the room furniture, which in- cluded a locker, desks, bookshelves, a screen, and so forth. The numbers $1-5$ in Figure 3 indicate the five viewing positions. From each position, several pieces of furniture and a number of stationary objects were observed as targets. The appendix shows the viewing position, viewing distance, and objective size (width) of 29 targets estimated by the subject. Eleven targets were used for both distance and size estimations, 1 target was used for distance estimation only, and 17 targets were used for size estimation only.

The subjects were 6 staff members ( 4 males and 2 females) and 24 undergraduates (16 males and 8 females) of the Tokyo University of Mercantile Marine; their ages ranged from 18 to 61 years. The subject sat in a chair at each of the five viewing positions and indicated the distance and/or size (width) of each target, with verbal estimates expressed in centimeters, meters, or some combination thereof. The subject was permitted to move his/her eyes and head freely, but was not permitted to get up from the chair. The order of the five viewing positions was randomized and, for a given viewing position, the estimation order of targets was randomized. No limitation of the time needed for estimation was imposed on the subject.

\section{RESULTS}

Figure 4 shows the geometric means of the distance estimates obtained for each experiment as a function of objective distance on log-log coordinates. Each data point is a geometric mean taken across subjects.

A power function was fitted to the geometric means of the distance estimates obtained in each experiment. Table 1 shows the slopes and intercepts that were obtained using the method of least squares, together with the coefficients of determination $\left(r^{2}\right)$. The slope obtained in each experiment was not significantly different from unity [for Experiment $1, F<1$; for Experiment $2, F(1,12)=4.72$, $.05<p<.10$; for Experiment $3, F<1]$. Thus, in all conditions, distance estimates were proportional to objective distance.

Figure 5 shows the geometric means of the size estimates obtained in each experiment as a function of objective size on $\log -\log$ coordinates. Each data point is a geometric mean taken across subjects.

A power function was fitted to the geometric means of the size estimates obtained in each experiment. Table 2 shows the slopes and intercepts that were obtained by using the method of least squares, together with the coefficients of determination $\left(r^{2}\right)$. The slopes obtained in each experiment were not significantly different from unity [for Experiment $1, F<1$; for Experiment $2, F<1$; for Experiment $3, F(1,9)=5.116, .05<p<.10$ ]. Thus, size estimates were proportional to objective size in any situation.

To determine the extent to which the results presented in Figures 4 and 5 might have been due to the scaling behavior unique to each subject, we obtained power functions that were fit to the size and distance estimates for each subject. Figure 6 plots the exponents for size estimates against the exponents for distance estimates. Each point is a subject. The correlations between the exponents were not significantly different from zero: -.063 for Experiment 1, .065 for Experiment 2, and .196 for Experiment 3 . Accordingly, it is impossible to predict the indi- 


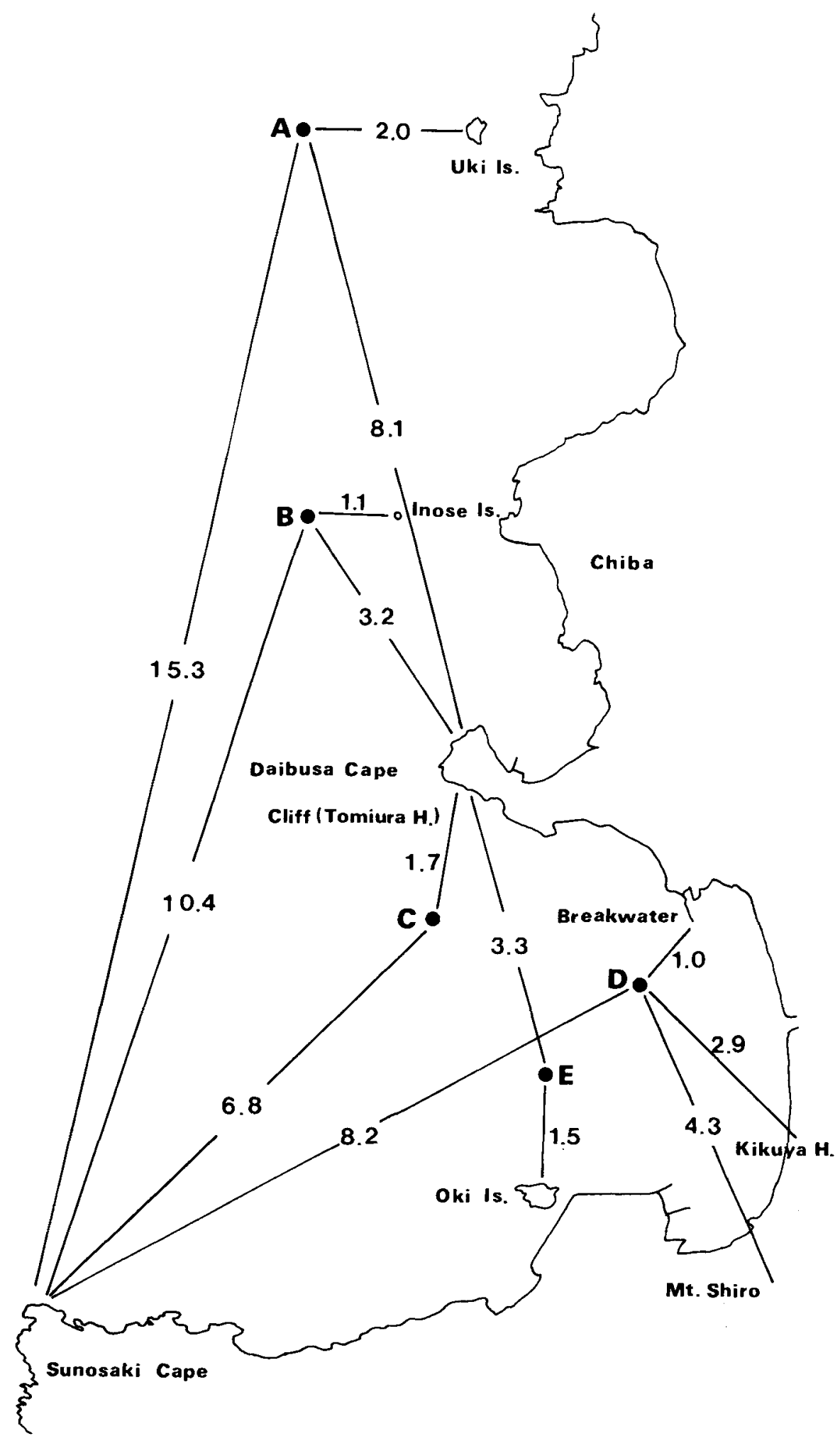

Figure 2. Various targets in Tateyama Bay and their distances in kilometers from each of five stop positions (A-E). 
Entrance

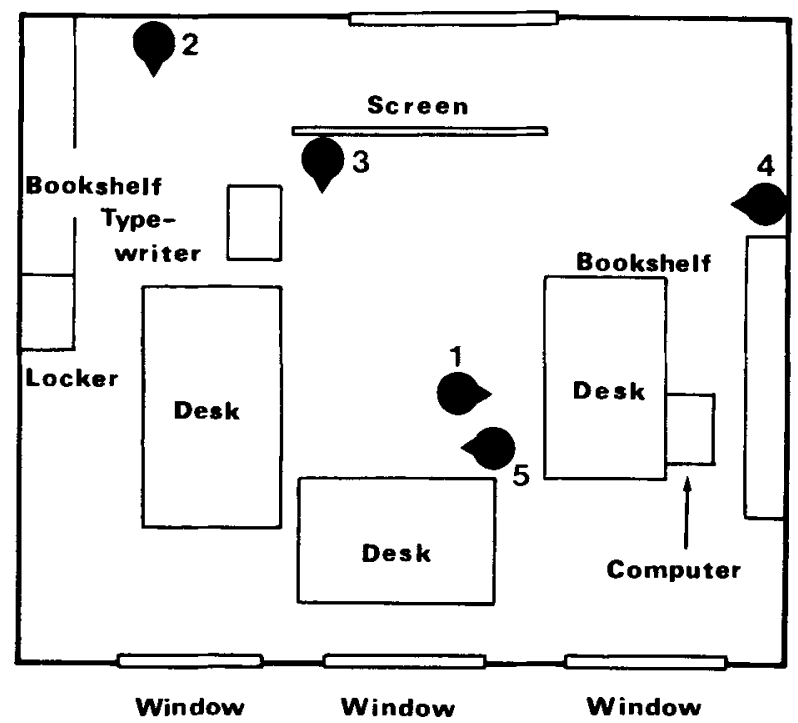

Figure 3. Various targets and five viewing positions (1-5) in a wellilluminated room. The arrows show the direction toward which the subject looked.

vidual exponents for size estimates from those for distance estimates. The standard deviations $(S D \mathrm{~s})$ of exponents for size estimates were 1.05, 0.283, and 0.052 for Experiments 1, 2, and 3, respectively; the $S D$ s of exponents for distance estimates were $0.270,0.255$, and 0.116 for Experiments 1,2 and 3 , respectively.

Similarly, Figure 7 plots the individual intercepts for size estimates against individual intercepts for distance estimates. The correlation between the intercepts in Experiment 1 was significantly different from zero $(r=$ $.463, p<.01$ ), but the correlations for Experiment 2 $(r=-.057)$ and Experiment $3(r=-.009)$ were not significant. This means that, in Experiment 1, the subjects who were likely to use large numbers in distance estimation were also likely to use large numbers in size estimation, but such a tendency was not found in the other experiments. The $S D$ s of intercepts for size estimates were $0.455,0.581$, and 0.083 in Experiments 1, 2, and 3, respectively; the $S D$ s of intercepts for distance estimates were $0.336,0.240$, and 0.260 in Experiments 1, 2, and 3 , respectively.

Table 3 shows the results for the objects for which the subjects estimated both distance and size. Figure 8 shows $S^{\prime} / D^{\prime}$, which was computed from Table 3 , as a function of visual angle. The parameter is the experiment. Equation 3 was fitted by the least squares method to $S^{\prime} / D^{\prime}$ as a function of $\theta$. The obtained equation was $S^{\prime} / D^{\prime}=$ $0.023 \theta^{0.94}\left(r^{2}=.978\right)$ for Experiment 2 , and $S^{\prime} / D^{\prime}=$ $0.019 \theta^{1.07}\left(r^{2}=.987\right)$ for Experiment 3. The equation for Experiment 1 was not obtained because of the small sample size $(n=3)$.

For comparison, the results obtained by Foley (1968) and Oyama (1974), in which one or two targets were ob- served with a stereoscope in otherwise total darkness, are depicted in Figure 8: Foley's curve is $S^{\prime} / D^{\prime}=0.018 \theta^{1.38}$, and Oyama's curve is $S^{\prime} / D^{\prime}=0.012 \theta^{1.52}$. Clearly, the exponents obtained in this study were smaller than those obtained under stereoscopic vision.

Equation 4 was fitted to the same data by the least squares method. The resulting equation was $S^{\prime} / D^{\prime}=$ $\tan (1.07 \theta+0.64)\left(r^{2}=.916\right)$ for Experiment 2 , and $S^{\prime} / D^{\prime}=\tan (1.23 \theta+0.16)\left(r^{2}=.991\right)$ for Experiment 3. Thus, Equation 4 accounted for the data as well as did Equation 3.
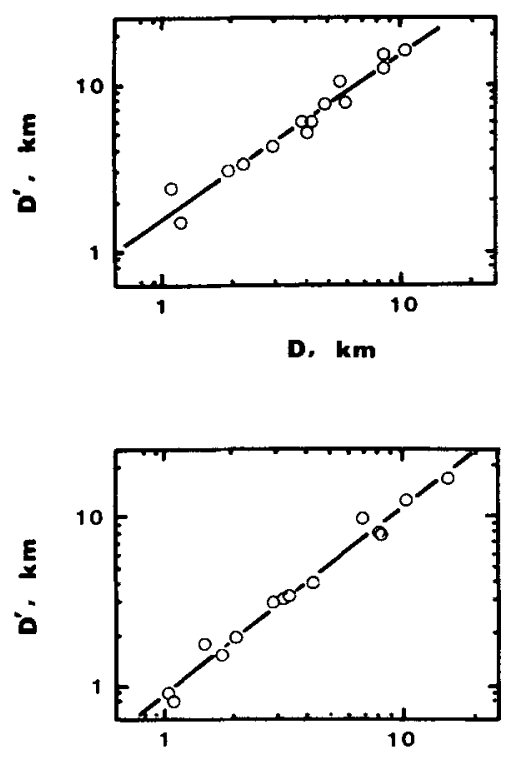

D. $\mathbf{k m}$

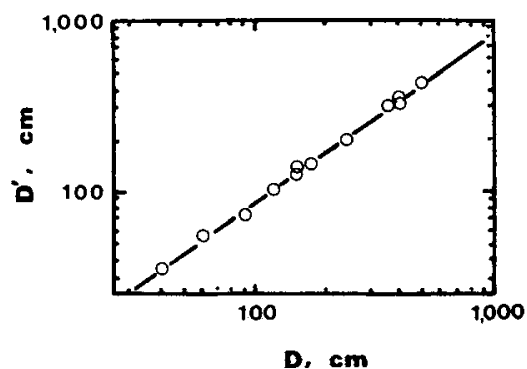

Figure 4. Geometric mean of distance estimates obtained in each experiment as a function of objective distance. The top panel is for Experiment 1, the middle for Experiment 2, and the bottom for Experiment 3.

Table 1

Slopes and Intercepts of the Power Functions Obtained for Distance Estimates by the Method of Least Squares, Together With Coefficients of Determination $\left(r^{2}\right)$

\begin{tabular}{ccccc}
\hline Experiment & $n$ & Slope & Intercept & $r^{2}$ \\
\hline 1 & 14 & 0.987 & 0.195 & .954 \\
2 & 14 & 1.096 & -0.0486 & .980 \\
3 & 12 & 0.992 & -0.0446 & .996 \\
\hline
\end{tabular}

Note $-n=$ sample size. 

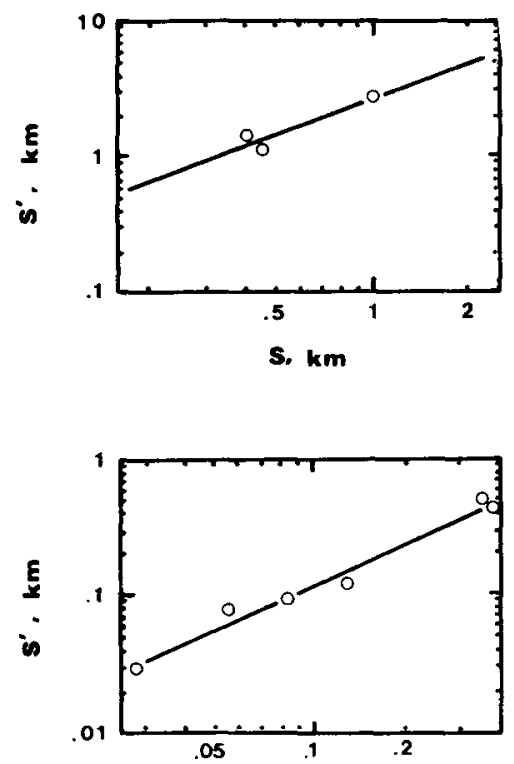

S. $\mathbf{k m}$

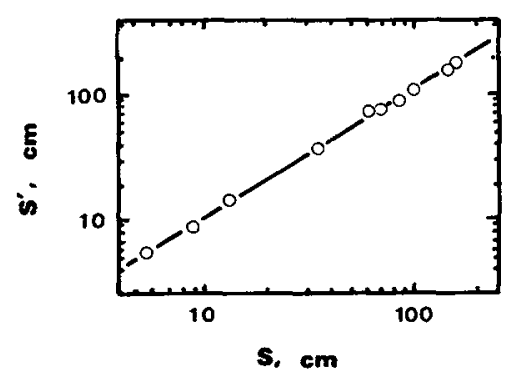

Figure 5. Geometric mean of size estimates obtained in each experiment as a function of object size. The top panel is for Experment 1, the middle for Experiment 2, and the bottom for Experiment 3.

On the other hand, Equation 2, which is also depicted in Figure 8, was far from satisfactory as a description of the data. Most of the points plotted in Figure 8 deviate systematically from the curve predicted from Equation 2. To demonstrate further that Equation 2 is not appropriate, the geometric means of individual values of $D^{\prime} \tan \theta$ were computed for each target and are shown in the column $s$ in Table 3 . The $s$ value is considered to be the size estimates predicted from the taking-into-account model. A series of paired-sample $t$ tests indicated that for 14 of the 20 objects, $S^{\prime}$ was significantly larger than $s$, and for the remaining 6 objects, there was not a significant difference between the two. The last column in Table 3 shows the $t$ values with significance level. The mean overestimation of size $\left(S^{\prime} / s\right)$ that was taken across objects was $1.37(S D=0.29)$, which was significantly larger than unity $[t(19)=5.53, p<.01]$.

From the results shown in Table 3, simple and partial correlations were calculated between each stimulus $(D$, $S$, or $\theta)$ and each response $\left(D^{\prime}\right.$ or $\left.S^{\prime}\right)$, and between $D^{\prime}$ and $S^{\prime}{ }^{1}$ The results are shown in Table 4 . For the longdistance conditions, the combined data of Experiments 1 and 2 and the data of Experiment 2 were analyzed separately. The data of Experiment 1 were not analyzed, because of the small sample size. Simple correlation is the usual correlation between two variables in question; partial correlation is a net correlation between two variables, which is obtained after removing the effects of other variables on the two.

For the long-distance conditions, the patterns of simple correlations for the two sets of data were very similar

Table 2

Slopes and Intercepts of the Power Functions Obtained for Size Estimates by the Method of Least Squares, Together With Coefficients of Determination $\left(r^{2}\right)$

\begin{tabular}{crrrr}
\hline Experiment & $n$ & Slope & Intercept & $r^{2}$ \\
\hline 1 & 3 & 0.865 & 0.825 & .862 \\
2 & 6 & 1.038 & 0.0995 & .975 \\
3 & 28 & 1.030 & -0.0115 & .997 \\
\hline
\end{tabular}

Note $-n=$ sample size.
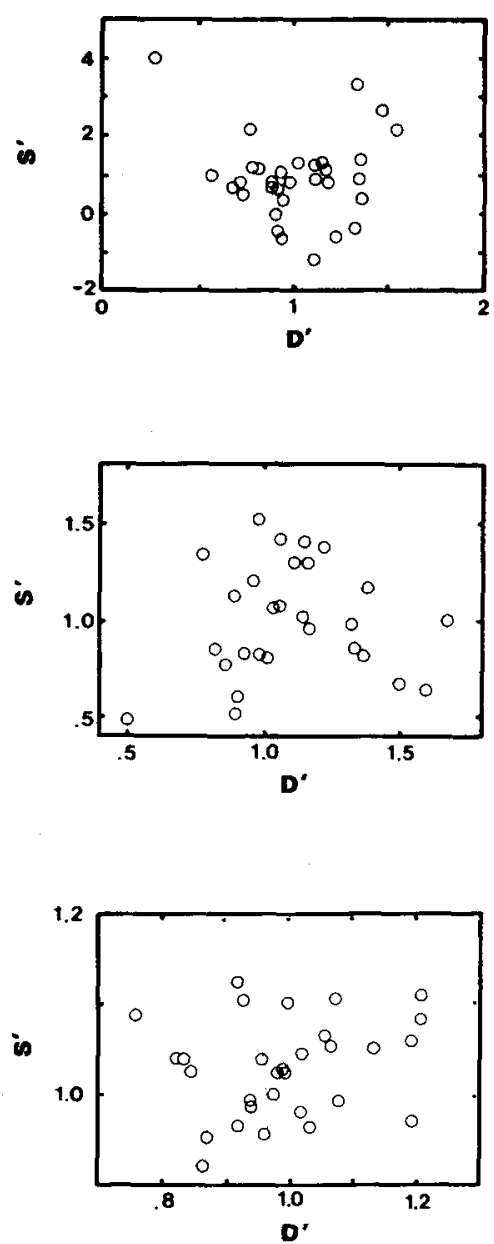

Figure 6. A relation between individual exponents for distance estimates and individual exponents for size estimates. The top panel is for Experiment $1(n=34)$, the middle for Experiment 2 ( $n=$ 28), and the bottom for Experiment $3(n=30)$. 

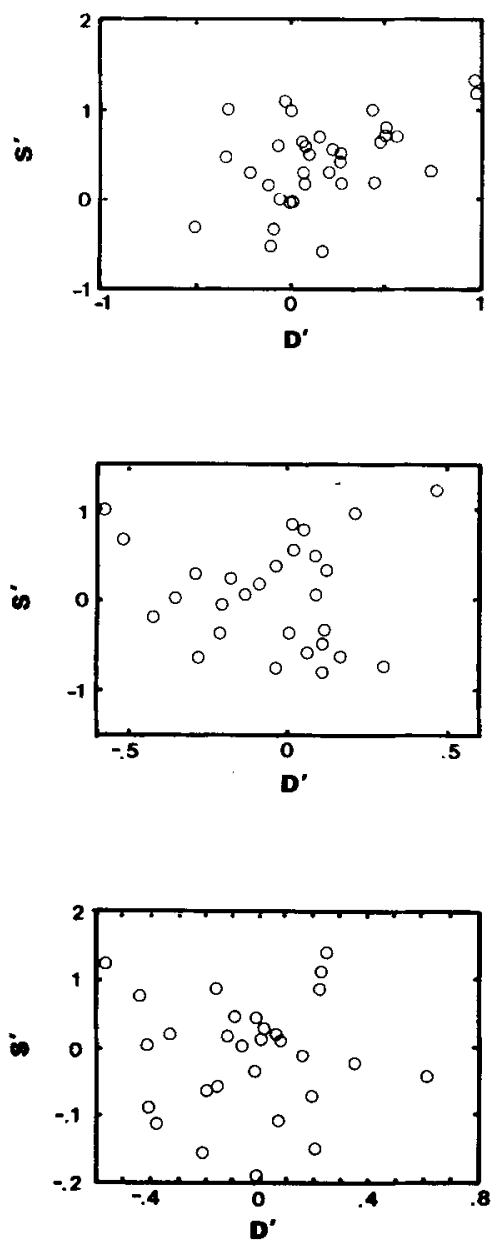

Figure 7. A relation between individual intercepts for distance estimates and individual intercepts for size estimates. The top panel is for Experiment $1(n=34)$, the middle for Experiment $2(n=$ $28)$, and the bottom for Experiment $3(n=30)$.

to one another: Significantly high correlations were obtained between $D$ and $D^{\prime}$, between $S$ and $S^{\prime}$, and between $\theta$ and $S^{\prime}$. On the other hand, the patterns of partial correlations were different between the two sets of data: For the combined data, significantly high partial correlations were obtained between $D$ and $D^{\prime}$ and between $S$ and $S^{\prime}$; for the data of Experiment 2, significantly high partial correlations were obtained for all pairs of variables.

The results for either set of data are not completely explained by the taking-into-account model, which predicts high partial correlations between $\theta$ and $S^{\prime}$ and between $D^{\prime}$ and $S^{\prime}$, and a low partial correlation between $\theta$ and $D^{\prime}$. For the combined data, we did not obtain high partial correlations between $\theta$ and $S^{\prime}$ and between $D^{\prime}$ and $S^{\prime}$; for the data of Experiment 2, we did not obtain a low partial correlation between $\theta$ and $D^{\prime}$. Note that the partial correlation between $S^{\prime}$ and $D^{\prime}$ was low for the combined data but was high for the data of Experiment 2. This means that the direct-perception model held for the combined data, but not for the data of Experiment 2.
In Experiment 3, we obtained significantly high partial correlations between $D$ and $D^{\prime}$ and between $S$ and $S^{\prime}$ and a low partial correlation between $S^{\prime}$ and $D^{\prime}$. Clearly, these results are in perfect agreement with the prediction from the direct-perception model, rather than from the taking-into-account model.

\section{DISCUSSION}

An important finding presented from Table 1 is that, over the distances of $40 \mathrm{~cm}$ to $15 \mathrm{~km}$, the distance estimates were related to objective distance by a power function with an exponent of unity. Similarly, as is clear in Table 2, size estimates were related to objective size by a power function with an exponent of unity, regardless of whether the objects were viewed from a short distance or a long distance. In other words, size and distance estimates vary in proportion to objective size and distance, respectively.

From these accurate mean estimates, however, it is premature to conclude that there was no difference in size and distance estimation between the short- and longdistance conditions. Note the remarkable individual differences in exponents for both size and distance estimates in the long-distance conditions. The $S D$ s of individual exponents of size for the long-distance conditions ( 1.05 and 0.28 ) were much larger than the $S D$ for the short-distance condition (0.05). Similarly, the $S D$ s of individual exponents of distance for the long-distance conditions $(0.27$ and 0.25 ) were about twice as large as the $S D$ for the shortdistance condition $(0.12)$. Thus, it is difficult to predict individual exponents of size and distance for very far objects, even if the mean exponent taken across subjects is easily predictable.

\section{Long Outdoor Distance}

The distance estimates obtained for very far objects challenge the results of Galanter and Galanter (1973), who showed distance estimates to increase more rapidly than

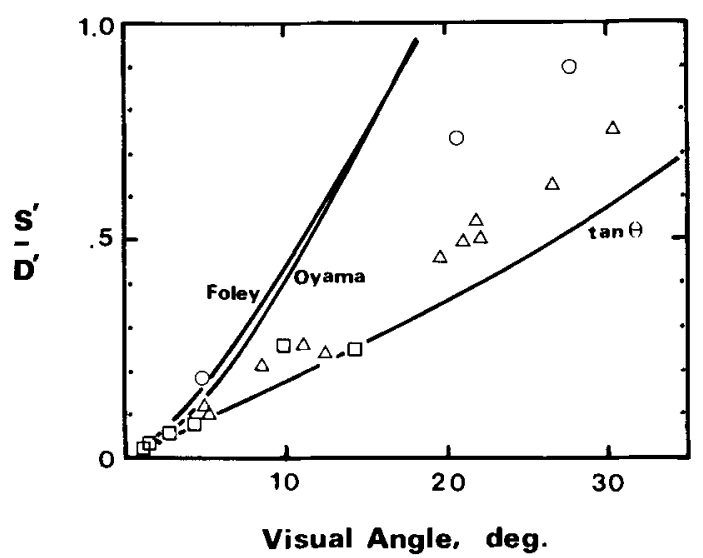

Figure 8. $S^{\prime} / D^{\prime}$ as a function of visual angle $\theta$ in degrees. The parameter is the experiment: circle = Experiment 1; square $=$ Experiment 2; triangle $=$ Experiment 3 . See text for the three curves. 
Table 3

Objective Distance $(D)$, Objective Size $(S)$, Visual Angle $(\theta)$ in Degrees, Reported Distance $\left(D^{\prime}\right)$, Reported Size $\left(S^{\prime}\right)$, and Size Estimates Predicted From the Taking-Into-Account Model (s)

\begin{tabular}{|c|c|c|c|c|c|c|c|}
\hline Object & $D$ & $S$ & $\theta(\mathrm{deg})$ & $D^{\prime}$ & $S^{\prime}$ & $s$ & $t$ \\
\hline \multicolumn{8}{|c|}{ Experiment 1} \\
\hline Matsu Island & 1.2 & 0.45 & 20.6 & 1.5 & 1.1 & 0.56 & $6.28 \ddagger$ \\
\hline Kama Island* & 1.9 & 1.00 & 27.8 & 3.0 & 2.7 & 1.55 & $3.81 \ddagger$ \\
\hline Koyo Island & 4.8 & 0.40 & 4.8 & 7.6 & 1.4 & 0.63 & $6.09 \ddagger$ \\
\hline \multicolumn{8}{|c|}{ Experiment 2} \\
\hline Uki Island & 2.02 & 0.35 & 9.89 & 1.95 & 0.50 & 0.34 & $2.50 \dagger$ \\
\hline Inose Island & 1.10 & 0.028 & 1.46 & 0.82 & 0.029 & 0.021 & 1.46 \\
\hline Oki Island & 1.49 & 0.38 & 14.31 & 1.74 & 0.43 & 0.44 & 0.32 \\
\hline Cliff & 1.75 & 0.084 & 2.75 & 1.53 & 0.092 & 0.073 & 1.56 \\
\hline Tomiura Hotel & 1.75 & 0.13 & 4.25 & 1.53 & 0.12 & 0.11 & 0.58 \\
\hline Kikuya Hotel & 2.90 & 0.055 & 1.09 & 3.11 & 0.078 & 0.059 & $2.39 \dagger$ \\
\hline \multicolumn{8}{|c|}{ Experiment 3} \\
\hline Keyboard & 40 & 8.9 & 12.5 & 36.2 & 8.6 & 8.1 & 1.12 \\
\hline Display & 90 & 34.6 & 21.0 & 73.3 & 36.2 & 28.2 & $4.88 \ddagger$ \\
\hline Bond & 60 & 5.4 & 5.14 & 55.0 & 5.5 & 4.9 & 1.78 \\
\hline Window 1 & 500 & 98.5 & 11.1 & 439.5 & 111.9 & 86.6 & $7.07 \ddagger$ \\
\hline Apparatus 2 & 170 & 85.0 & 26.6 & 145.9 & 91.8 & 73.0 & $5.38 \ddagger$ \\
\hline File & 400 & 60.5 & 8.60 & 363.9 & 75.6 & 55.0 & $7.24 \ddagger$ \\
\hline Desk 1 & 360 & 145.8 & 22.0 & 320.6 & 160.7 & 128.4 & $5.36 \neq$ \\
\hline Bookshelf 1 & 400 & 160.0 & 21.8 & 331.1 & 180.7 & 132.4 & $7.43 \ddagger$ \\
\hline Desk 2 & 240 & 85.5 & 19.6 & 198.6 & 91.6 & 70.8 & $4.67 \ddagger$ \\
\hline Desk 3 & 120 & 70.0 & 30.3 & 102.8 & 77.4 & 60.0 & $6.49 \ddagger$ \\
\hline Box & 150 & 13.0 & 4.95 & 123.9 & 14.3 & 10.7 & $5.81 \ddagger$ \\
\hline
\end{tabular}

Note-In Experiments 1 and 2, distance and size values are expressed in kilometers. In Experiment 3, distance and size values are expressed in centimeters. For Experiments 1,2 , and $3, n s=36,28$, and 30 , respectively. $*_{n}=34$, due to lost data. $\dagger p<.05 . \quad \neq p<.001$.

Table 4

Simple and Partial Correlations Between Stimuli $(D, S$, and $\theta)$ and Responses $\left(D^{\prime}\right.$ and $\left.S^{\prime}\right)$, and Between $D^{\prime}$ and $S^{\prime}$

\begin{tabular}{|c|c|c|c|c|c|c|}
\hline \multirow{2}{*}{$\begin{array}{l}\text { Paired } \\
\text { Values }\end{array}$} & \multicolumn{2}{|c|}{$\begin{array}{c}\text { Experiments } 1 \text { and } 2 \\
(n=9)\end{array}$} & \multicolumn{2}{|c|}{$\begin{array}{c}\text { Experiment } 2 \\
(n=6)\end{array}$} & \multicolumn{2}{|c|}{$\begin{array}{l}\text { Experiment } 3 \\
(n=11)\end{array}$} \\
\hline & Simple & Partial & Simple & Partial & Simple & Partial \\
\hline$\left(D, D^{\prime}\right)$ & $.964 *$ & $.967^{*}$ & $.965^{*}$ & $.999^{*}$ & $.998 *$ & $.989 *$ \\
\hline$\left(S, S^{\prime}\right)$ & $.956^{*}$ & $.775^{*}$ & $.981^{*}$ & $.987^{*}$ & $.998^{*}$ & $.993^{*}$ \\
\hline$\left(D, S^{\prime}\right)$ & .235 & -.411 & -.020 & $-.911^{*}$ & $.774^{*}$ & -.118 \\
\hline$\left(S, D^{\prime}\right)$ & .262 & -.322 & .064 & $-.954 *$ & $.724 *$ & -.257 \\
\hline$\left(\theta, D^{\prime}\right)$ & -.064 & .300 & -.030 & $.975 *$ & -.042 & .208 \\
\hline$\left(\theta, S^{\prime}\right)$ & $.808^{*}$ & -.261 & $.922 *$ & $-.964 *$ & $-.520 \dagger$ & -.000 \\
\hline$\left(D^{\prime}, S^{\prime}\right)$ & .441 & .500 & .119 & $.907 *$ & $.753^{*}$ & .207 \\
\hline
\end{tabular}

objective distance. They also challenge the results of Nagahata (1980), who showed distance estimates to increase more slowly than objective distance. How is it possible that the distance estimates are proportional to objective distance? It seems difficult to explain it in terms of physiological distance cues, such as accommodation, binocular convergence, and binocular retinal disparity, since the effective distance of these cues is several meters. It also seems difficult to explain in terms of pictorial cues, such as texture gradient, light and shade, linear perspective, and interposition, because these cues may be effective for depth between objects, but not for egocentric distance.
The concept of familiar distance, which was not considered in the partial correlation analysis, may explain the distance estimates obtained for the long-distance conditions. Familiar distance means the remembered distance that is associated with a specific visual angle through the experience of seeing or walking. For example, many people sometimes run the $100-\mathrm{m}$ dash. When one stands at the starting line and sees the finish line at a distance, the two lines subtend a visual angle of about $89^{\circ}$ for a person $170 \mathrm{~cm}$ tall. If this specific visual angle is memorized and remembered to correspond to an objective distance of $100 \mathrm{~m}$, it is then possible to calculate other egocentric distances relative to this familiar distance: 


$$
D^{\prime}=D_{f}^{\prime} \frac{\tan \theta}{\tan \theta_{f}},
$$

where $D^{\prime}$ is the apparent egocentric distance, $\theta$ is the visual angle of egocentric distance, $\theta_{f}$ is the specific visual angle that is often seen in daily life, and $D_{f}^{\prime}$ is the remembered distance that is associated with $\theta_{f}$.

The size estimates obtained for the long-distance condition are easily explained if apparent distance is taken into account in estimating apparent size. Actually, the results of Experiment 2 obtained with the partial correlation analysis showed a significantly high correlation between $S^{\prime}$ and $D^{\prime}$. However, other aspects of the partial correlation analysis (i.e., a high positive correlation between $\theta$ and $D^{\prime}$ and a high negative correlation between $\theta$ and $S^{\prime}$ ) do not support the taking-into-account model. In addition, the partial correlations obtained for the combined data of Experiments 1 and 2 did not support the taking-into-account model.

It may also be difficult to explain the size estimates obtained for the long-distance condition by texture gradient given on the retina, because there was no or little texture gradient behind the very far stimulus targets. For example, several islands and capes, which were used as targets in Experiments 1 and 2, were seen in isolation. These targets were seen on the background of the sky and the sea. The sky does not provide texture gradient at all, and the waves on the sea may provide texture gradient only at short distances but not at long distances. It seems that the horizon line is information given only on the retina. Therefore, the obtained size estimates may be explained by the horizontal-ratio principle (Sedgwick, 1986), which predicts apparent size from the relation between the angular size of an object and the angular size between the horizon and the object's intersection with the ground plane, rather than predicting apparent size from the texture gradient.

The direct-perception model was supported by the partial correlations obtained for the combined data of Experiments 1 and 2, but was not supported by those obtained for the data of Experiment 2. Such a difference in the partial correlations may be due to the small sample size. Despite the failure of the model to fit the data consistently, both sets of data provided significantly high correlations between $S$ and $S^{\prime}$ and between $D$ and $D^{\prime}$. This suggests that size and distance estimations are affected strongly by external stimuli.

A prominent feature of the partial correlations obtained for the data of Experiment 2 is that the size and distance estimates were contaminated by a cognitive bias. The negative correlation between $D$ and $S^{\prime}$ indicates that a farther object appears smaller, and the negative correlation between $S$ and $D^{\prime}$ indicates that a smaller object appears more distant. These tendencies may resemble the perspective attitude - a belief that an object appears small at a great distance, even when size constancy actually prevails over long distance (Carlson, 1977). It is likely that when there is not much reliable external information for size estimation, the estimation is determined not only by the external information, but also by cognitive strategies, such as the perspective attitude. The intrusion of the perspective attitude into size estimation has been considered to distort size-constancy judgments and lead to overconstancy. It is, nevertheless, interesting that the size estimation was still proportional to objective size at long distances.

We also obtained a positive correlation between $\theta$ and $D^{\prime}$ and a negative correlation between $\theta$ and $S^{\prime}$ for Experiment 2. According to studies of relative-size cue to distance, an increase of visual angle increases apparent size and decreases apparent distance (Epstein \& Landauer, 1969; Gogel, 1964, 1969; Landauer \& Epstein, 1969). Clearly, our results were not in agreement with the operation of the relative-size cue. We do not have theories to explain this aspect of the results.

\section{Short Indoor Distance}

The size estimates obtained for the short-distance condition support the study of $\mathbf{R}$. Teghtsoonian and $\mathbf{M}$. Teghtsoonian (1970a), who showed that magnitude estimates for objects of fixed size are almost constant, independently of viewing distance in a naturalistic indoor setting. The distance estimates obtained for the short-distance condition are consistent with the study of Künnapas (1968), but not with studies of $\mathrm{M}$. Teghtsoonian and R. Teghtsoonian (1969) and Wiest and Bell (1985), who have noted that the exponent may be slightly larger than unity.

Why were the size and distance estimates proportional to objective size and distance, respectively? It is very likely that the accurate perception resulted from the rich spatial information. Since the indoor narrow space was filled with furniture, machinery, stationary objects, and so forth, the subject could make use of spatial information provided by binocular convergence and binocular retinal disparity, as well as fine-grained texture gradient on the floor, the walls, and the desks.

The size and distance estimates obtained in Experiment 3 can be explained by the direct-perception model, which assumes size and distance perception to be determined exclusively by external stimulation and not by internal processing. These results do not agree with the taking-into-account model, which assumes a high partial correlation between apparent size and apparent distance. In defense of the taking-into-account model, it is possible to suppose that the low partial correlation between size estimates and distance estimates does not reflect the true correlation between apparent size and apparent distance, because verbal judgments of size and distance are not considered as unbiased measures of apparent size and apparent distance (Gogel, 1990; Gogel \& Da Silva, 1987a, 1987b). In this case, the failure to support the taking-intoaccount model could be due to the biased responses of apparent size and distance. Several laboratory studies, in which points of light and familiar objects were viewed at distances of several meters or less, have suggested a 
linear relation, not an exact coincidence, between apparent distance and its verbal report. Gogel (1981) and Gogel and Tietz (1973) found the verbal report of distance to be $0.5-0.7$ of the distance the subject actually perceives. Foley (1985) indicated that manually indicated distance and verbally reported distance are linearly related under suitable transformation of these responses. If this linearity holds in this study as well, the correlation between size estimates and distance estimates is identical to the correlation between apparent size and apparent distance, because a correlation between two variables does not change under the linear transformation of each variable.

The results of Experiment 3 may agree with Oyama (1974), who discovered that both binocular convergence and retinal image size directly affect both apparent size and apparent distance but that there is not a significantly high correlation between apparent size and apparent distance. However, there are two studies suggesting that apparent distance (or depth) is taken into account in size estimation. Oyama (1977, Table 3) obtained high partial correlations between apparent size and apparent distance for the unpublished study of Mori and Watase, in which verbal estimates of size and distance for illuminated disks were obtained in otherwise total darkness. Meer (1979) indicated that when binocular disparity and linear perspective cues are available, these cues affect apparent size and apparent depth, and, at the same time, apparent depth affects apparent size. Accordingly, taken together with our results for the long-distance conditions, the causal network of apparent size and apparent distance may vary with the situation.

\section{Form of the $S^{\prime} / D^{\prime}$ Function}

Equation 2 did not provide a good fit to the data. The obtained values of $S^{\prime} / D^{\prime}$ mostly deviated from the values predicted from visual angles. This suggests that a relation among apparent size, apparent distance, and visual angle does not correspond rigidly to the physical relation.

Rather, Equations 3 and 4 provided a good fit to the data, probably because they have two free parameters. The ratio $S^{\prime} / D^{\prime}$ was related to visual angle by a power function with an exponent of unity. This is in contrast to the exponent of 1.45 obtained under stereoscopic vision. The exponent probably increases with a reduction of spatial cues. Under a full distance-cue condition, an increase of visual angle increases apparent size but does not affect apparent distance (Higashiyama \& Kitano, 1991), whereas under an extremely reduced distance-cue condition, an increase of visual angle increases apparent size and decreases apparent distance (Higashiyama, 1977, 1979). Therefore, the $S^{\prime} / D^{\prime}$ ratio as a function of visual angle may grow steeply in the reduced distance-cue conditions.

Even in the full distance-cue condition of Experiment 3, the obtained values of $S^{\prime} / D^{\prime}$ did not conform to Equation 2 , which assumes $S^{\prime} / D^{\prime}$ to be a function of visual angle; instead, these values were reasonably represented by Equation 4 , which assumes $S^{\prime} / D^{\prime}$ to be a function of apparent visual angle. Table 3 suggests that the mean visual angle of stimulus targets $\left(13.5^{\circ}\right)$ was perceived as $18.5^{\circ}$ on the average. This result may agree with previous studies (Higashiyama, 1987, 1992) that demonstrated that small visual angle is estimated to be twice as large and the ratio of estimated angle to actual angle decreases as a function of actual angle.

It is thus suggested that $S^{\prime} / D^{\prime}$ is represented suitably by the power function of apparent visual angle, with a steep exponent under a reduced distance-cue condition and with an exponent of unity under the full distance-cue condition. This suggestion does not lead to criticism of the studies in which Equation 2 was assumed. In most of these studies, size and distance estimates were obtained for $o b$ jects of $5^{\circ}$ of visual angle or less. For small visual angles, as is shown in Figure 8, it may be difficult to differentiate among Equations 2, 3, and 4.

\section{REFERENCES}

AKISHIGE, Y. (1961). Theoretical considerations on the problems of perceptual constancies. Bulletin of the Faculty of Literature of Kyushu University, 7, 1-58.

Asher, H. B. (1976). Causal modeling. Beverly Hills, CA: Sage.

BAIRD, J. C. (1982). The moon illusion: II. A reference theory. Journal of Experimental Psychology: General, 111, 304-315.

BAIRD, J. C., \& BIERSDORF, W. R. (1967). Quantitative functions for size and distance judgments. Perception \& Psychophysics, 2, 161-166.

BaIRD, J. C., \& Wagner, M. (1982). The moon illusion: I. How high is the sky? Joumal of Experimental Psychology: General, 111, 296-303.

BaiRd, J. C., \& Wagner, M. (1991). Transformation theory of size judgment. Journal of Experimental Psychology: Human Perception \& Performance, 17, 852-864.

CARLSON, V. R. (1977). Instructions and perceptual constancy judgments. In W. Epstein (Ed.), Stability and constancy in visual perception: Mechanisms and processes (pp. 217-254). New York: Wiley.

CARLSON, V. R., \& TASSONE, E. P. (1967). Independent size judgments at different distances. Journal of Experimental Psychology, 73, $491-497$.

Cohen, J., \& Cohen, P. (1975). Applied multiple regression/correlation analysis for the behavioral sciences. New York: Wiley.

Cook, M. (1978). The judgment of distance on a plane surface. Perception \& Psychophysics, 23, 85-90.

DA Silva, J. A. (1985). Scales for perceived egocentric distance in a large open field: Comparison of three psychophysical methods. American Journal of Psychology, 98, 119-148.

EPsteIN, W. (1963). Attitude of judgment and the size-distance invariance hypothesis. Journal of Experimental Psychology, 66, 78-83.

EPSTEIN, W. (1973). The process of "taking-into-account" in visual perception. Perception, 2, 267-285.

EPSTEIN, W. (1977). Historical introduction to the constancies. In W. Epstein (Ed.), Stability and constancy in visual perception: Mechanisms and processes (pp. 1-22). New York: Wiley.

Epstein, W., \& LANDauer, A. A. (1969). Size and distance judgments under reduced conditions of viewing. Perception \& Psychophysics, 6, 269-272.

EPstein, W., Park, J., \& CaSEy, A. (1961). The current status of the size-distance hypotheses. Psychological Bulletin, 58, 491-514.

ERIKSSON, S., \& ZETTERBERG, P. (1975). Experience and veridical space perception: An ecological experiment (Rep. 169). Department of Psychology, University of Uppsala, Uppsala, Sweden.

FOLEX, J. M. (1965). Visual space: A scale of perceived relative direction. Proceedings of the 73rd Annual Convention of the American Psychological Association, 1, 49-50.

FoleY, J. M. (1967). Binocular disparity and perceived relative distance: An examination of two hypotheses. Vision Research, 7, 655-670. 
Foley, J. M. (1968). Depth, size and distance in stereoscopic vision. Perception \& Psychophysics, 3, 265-274.

FoLEY, J. M. (1985). Binocular distance perception: Egocentric distance tasks. Journal of Experimental Psychology: Human Perception \& Performance, 11, 133-149.

Galanter, E., \& Galanter, P. (1973). Range estimates of distant visual stimuli. Perception \& Psychophysics, 14, 301-306.

Gibson, E. J., \& Bergman, R. (1954). The effects of training on absolute estimation of distance over the ground. Journal of Experimental Psychology, 48, 473-482.

Gibson, E. J., BERGMAN, R., \& Purdy, J. (1955). The effect of prior training with a scale of distance on absolute and relative judgments of distance over the ground. Journal of Experimental Psychology, $\mathbf{5 0}$, 97-105.

GiBson, J. J. (1950). The perception of the visual world. Boston: Houghton Mifflin.

Gibson, J. J. (1979). The ecological approach to visual perception. Boston: Houghton Mifflin.

GiLinsky, A. S. (1951). Perceived size and distance in visual space. Psychological Review, 58, 460-482.

Gilinsky, A. S. (1955). The effect of attitude upon the perception of size. American Joumal of Psychology, 68, 173-192.

GoGel, W. C. (1964). Size cue to visually perceived distance. Psychological Bulletin, 62, 217-235.

GogeL, W. C. (1969). The sensing of retinal size. Vision Research, 9, 1079-1094.

GoGEL, W. C. (1981). The role of suggested size in distance responses. Perception \& Psychophysics, 30, 149-155.

GoGEL, W. C. (1990). A theory of phenomenal geometry and its applications. Perception \& Psychophysics, 48, 105-123.

Gogel, W. C., DA Silva, J. A. (1987a). A two-process theory of the response to size and distance. Perception \& Psychophysics, 41, 220-238.

Gogel, W. C., \& DA Silva, J. A. (1987b). Familiar size and the theory of off-sized perception. Perception \& Psychophysics, 41, 318-328.

GoGEL, W. C., \& TIETZ, J. D. (1973). Absolute motion parallax and the specific distance tendency. Perception \& Psychophysics, 13, 284-292.

GoldSTEIN, E. B. (1989). Sensation and perception (3rd ed.). Belmont, CA: Wadsworth.

HARWAY, N. I. (1963). Judgment of distance in children and adults. Journal of Experimental Psychology, 65, 385-390.

Higashiyama, A. (1977). Perceived size and distance as a perceptual conflict between two processing modes. Perception \& Psychophysics, 22, 206-211.

Higashiyama, A. (1979). The perception of size and distance under monocular observation. Perception \& Psychophysics, 26, 230-234.

Higashiyama, A. (1987). Ryoganshi kukan to fukuso no kino [Role of convergence in binocular space perception]. Japanese Psychological Monographs (No. 18).

Higashiy ama, A. (1992). Anisotropic perception of visual angle: Implications for the horizontal-vertical illusion, overconstancy of size, and the moon illusion. Perception \& Psychophysics, 51, 218-230.

Higashiyama, A., \& Kitano, S. (1991). Perceived size and distance of persons in natural outdoor settings: The effects of familiar size. Psychologia, 34, 188-199.

Higashiyama, A., \& TASHIRo, T. (1989). Magnitude estimates for electrical pulses: Evidence for two neural mechanisms. Perception \& Psychophysics, 45, 537-549.

InDow, T. (1991). A critical review of Luneburg's model with regard to global structure of visual space. Psychological Review, 98, 430-453.

Joynson, R. B., Newson, L. J., \& MAY, D. S. (1965). The limits of over-constancy. Quarterly Journal of Experimental Psychology, 17, 209-216.

Kaufman, L. (1974). Sight and mind: An introduction to visual perception. New York: Oxford University Press.

Kilpatrick, F. P., \& ItTelson, W. H. (1953). The size-distance invariance hypothesis. Psychological Review, 60, 223-231

KüNNAPAS, T. (1968). Distance perception as a function of available visual cues. Journal of Experimental Psychology, 77, 523-529.

Kuroda, T. (1971). Distance constancy: Functional relationships be- tween apparent distance and physical distance. Psychologische Forschung, 34, 199-219.

Landauer, A. A., \& Epstein, W. (1969). Does retinal size have a unique correlate in perceived size? Perception \& Psychophysics, 6 , 273-275.

Leibowitz, H. W., \& Harvey, L. O., JR. (1967). Size matching as a function of instructions in a naturalistic environment. Journal of Experimental Psychology, 74, 378-382.

Leibowitz, H. W., \& HaRVEY, L. O., JR. (1969). Effects of instructions, environment, and type of test objects on matched size. Journal of Experimental Psychology, 81, 36-43.

LUNEBURG, R. K. (1947). Mathematical analysis of binocular vision. Princeton: Princeton University Press.

McCready, D. W. (1965). Size-distance perception and accommodation-convergence micropsia-A critique. Vision Research, 5, 189-206.

MCCrEAdY, D. [W.] (1985). On size, distance, and visual angle perception. Perception \& Psychophysics, 37, 323-334.

McCready, D. [W.] (1986). Moon illusion redescribed. Perception \& Psychophysics, 39, 64-72.

MEER, H. C. VAN DER (1979). Interrelation of the effects of binocular disparity and perspective cues on judgments of depth and height. Perception \& Psychophysics, 26, 481-488.

Nagahata, T. (1980). Hiko no handan to sojusha no tokusei [The characteristics of navigators on maneuvers for avoiding collision]. $\mathrm{Ni}$ hon Kokai Gakkai Ronbun Shu, 63, 19-28.

NisHI, T. (1930). Okuyuki chikaku genkai to shi-kukan kozo [The limit of depth perception and the structure of visual space]. Shinrigaku Ronbun Shu, 5, 270-275.

ONo, H. (1970). Some thoughts on different perceptual tasks related to size and distance. Psychonomic Monographs Supplement, 3, (13, Whole No. 45).

Oyama, T. (1974). Perceived size and perceived distance in stereoscopic vision and an analysis of their causal relations. Perception \& Psychophysics, 16, 175-181.

OYAMA, T. (1977). Analysis of causal relations in the perceptual constancies. In W. Epstein (Ed.), Stability and constancy in visual perception: Mechanisms and processes (pp. 183-216). New York: Wiley.

Plug, C., \& Ross, H. E. (1989). Historical review. In M. Mershenson (Ed.), The moon illusion (pp. 5-27). Hillsdale, NJ: Erlbaum.

Purdy, J., \& Gibson, E. J. (1955). Distance judgment by the method of fractionation. Joumal of Experimental Psychology, 50, 374-390.

Rock, I. (1975). An introduction to perception. New York: Macmillan.

Ross, H. E., \& Ross, G. M. (1976). Did Ptolemy understand the moon illusion? Perception, 5, 377-385.

SEDGwick, H. A. (1986). Space perception. In K. R. Boff, L. Kaufman, \& J. P. Thomas (Eds.), Handbook of perception and human performance: Vol. 1. Sensory processes and perception (pp. 21.121.57). New York: Wiley.

Simon, H. A. (1954). Spurious correlation: A causal interpretation. Journal of the American Statistical Association, 49, 467-479.

SмIтн, W. M. (1953). A methodological study of size-distance perception. Journal of Psychology, 35, 143-153.

TADA, H. (1956). Okuyuki chikaku ni okeru enpo kyori no kadaishi [Overestimation of farther distance in depth perception]. Japanese Journal of Psychology, 27, 204-208.

Teghtsoonian, M., \& Teghtsoonian, R. (1969). Scaling apparent distance in natural indoor setting. Psychonomic Science, 16, 281-283.

TEGHTSOONIAN, R. (1973). Range effects in psychophysical scaling and a revision of Stevens's law. American Joumal of Psychology, 86, 3-27.

Teghtsoonian, R., \& Teghtsoonian, M. (1970a). The effects of size and distance on magnitude estimations of apparent size. American Journal of Psychology, 83, 601-612.

Teghtsoonian, R., \& Teghtsoonian, M. (1970b). Scaling apparent distance in natural outdoor setting. Psychonomic Science, 21, 215-216.

UENO, T. (1962). The size-distance invariance hypothesis and the psychophysical law. Japanese Psychological Research, 4, 99-112.

WIEST, W. M., \& BELL, B. (1985). Stevens's exponent for psychophysical scaling of perceived, remembered, and inferred distance. Psychological Bulletin, 98, 457-470.

WoHLwILl, J. F. (1963). The development of "overconstancy" in space perception. In L. L. Lipsitt \& C. C. Spiker (Eds.), Advances in child 
development and behavior (Vol. 1, pp. 265-312). New York: Academic Press.

\section{NOTE}

1. In making these calculations, we assumed that (1) apparent size may be influenced by the three objective variables $(S, D$, and $\theta)$ and apparent distance, and (2) apparent distance may be influenced by the same objective variables and apparent size. From the first assumption, we may obtain

$$
S^{\prime}=B_{S^{\prime} S^{\prime}} S+B_{S^{\prime} D} D+B_{S^{\prime} \theta} \theta+B_{S^{\prime} D^{\prime}} D^{\prime}+A_{S^{\prime}},
$$

and from the second assumption, we may obtain

$$
D^{\prime}=B_{D^{\prime} S} S+B_{D^{\prime} D} D+B_{D^{\prime} \theta} \theta+B_{D^{\prime} S^{\prime}} S^{\prime}+A_{D^{\prime}},
$$

where $A_{S^{\prime}}$ and $A_{D^{\prime}}$ are regression constants and the notation $B_{S}$ (e.g., $B_{S^{\prime} S}$ and $B_{D^{\prime} S}$ ) are partial regression coefficients. In each multiple linear regression, if the partial correlation between two variables in question

\begin{tabular}{|c|c|c|c|}
\hline \multicolumn{4}{|c|}{$\begin{array}{l}\text { APPENDIX } \\
\text { Viewing Position, Physical Distance (in Centimeters), and } \\
\text { Physical Size (in Centimeters) of the } 29 \text { Objects Used } \\
\text { in Experiment } 3\end{array}$} \\
\hline Object & Position & $\begin{array}{l}\text { Physical } \\
\text { Distance }\end{array}$ & $\begin{array}{c}\text { Physical } \\
\text { Size }\end{array}$ \\
\hline \multicolumn{4}{|c|}{ Judgments of Both Distance and Size } \\
\hline 1. Keyboard & 1 & 40 & 8.9 \\
\hline 2. Display & 1 & 90 & 34.6 \\
\hline 3. Bond & 1 & 60 & 5.4 \\
\hline 4. Window 1 & 2 & 500 & 98.5 \\
\hline 5. Apparatus 2 & 2 & 170 & 85.0 \\
\hline 6. File & 3 & 400 & 60.5 \\
\hline 7. Desk 1 & 3 & 360 & 145.8 \\
\hline 8. Bookshelf 1 & 4 & 400 & 160.0 \\
\hline 9. Desk 2 & 4 & 240 & 85.5 \\
\hline 10. Desk 3 & 5 & 120 & 70.0 \\
\hline 11. Box & 5 & 150 & 13.0 \\
\hline \multicolumn{4}{|c|}{ Distance Judgments Only } \\
\hline 12. Bookshelf 3 & 1 & 150 & 80.0 \\
\hline \multicolumn{4}{|c|}{ Size Judgments Only } \\
\hline 13. Book 1 & 1 & 60 & 1.4 \\
\hline 14. Book 2 & 1 & 60 & 10.8 \\
\hline 15. Dictionary 1 & 1 & 60 & 18.9 \\
\hline 16. Bookend 1 & 1 & 60 & 35.5 \\
\hline 17. Window 2 & 2 & 500 & 229.4 \\
\hline 18. Apparatus 1 & 2 & 500 & 15.0 \\
\hline 19. Picture & 3 & 400 & 17.8 \\
\hline 20. Letter case & 3 & 400 & 25.4 \\
\hline 21. Locker & 4 & 400 & 45.5 \\
\hline 22. Bookshelf 2 & 4 & 400 & 240.0 \\
\hline 23. Briefcase & 4 & 400 & 42.5 \\
\hline 24. Bookend 2 & 4 & 400 & 21.5 \\
\hline 25. Bottle & 4 & 400 & 3.9 \\
\hline 26. Apparatus 3 & 4 & 400 & 142.0 \\
\hline 27. Toolbox & 5 & 120 & 42.0 \\
\hline 28. Dictionary 2 & 5 & 120 & 22.0 \\
\hline 29. Cassette tape & 5 & 120 & 1.4 \\
\hline
\end{tabular}
is zero, then the partial regression coefficient is also zero.

(Manuscript received May 4, 1993;

revision accepted for publication October 6, 1993.) 